\title{
Atletas em movimento: abordagem teórica às migrações de trabalho desportivo
}

\author{
Athletes in motion: \\ theoretical approach to migrations of workers of sport \\ Atletas en movimiento: \\ enfoque teórico a las migraciones de trabajo deportivo \\ CARLOS Nolasco ${ }^{1}$ \\ Universidade de Coimbra, UC, Coimbra, Portugal
}

\begin{abstract}
RESUMO
No desporto contemporâneo é comum encontrar atletas a representar equipas de nacionalidades que não a sua, sendo que em algumas modalidades os jogadores estrangeiros se encontram em maioria em relação aos nacionais. Por outro lado é também comum constatar a presença de atletas que, em virtude de mudança de nacionalidade, representam outros países que não o seu. Estas situações resultam de migrações de trabalho desportivo, em que os atletas à semelhança de outros trabalhadores atravessam fronteiras de países, impelidos por forças sociais, políticas e económicas que os transcendem. As abordagens teóricas feitas a este fenómeno, apesar de recentes, permitem uma compreensão ampla das dinâmicas e complexidades. Este texto propõe-se problematizar as migrações de trabalho desportivo no âmbito das migrações gerais, revisitando as elaborações teóricas que interpretaram esta mobilidade de atletas.
\end{abstract}

Palavras-chave: Migrações. Migrações de Trabalho Desportivo. Desporto. Globalização. Sistema-Mundo.

\begin{abstract}
In contemporary sport it is common to find athletes representing teams of nationalities other than their own, and in some sports foreign players are majority compared to national players. On the other hand, it is also common to note the presence of athletes who, due to the change of nationality, represent other countries than their country of birth. These situations result from the migration of workers of sport, in which athletes, like other workers, cross country borders driven by social, political and economic forces that transcend them. The theoretical approaches to this phenomenon, although recent, allow a broad understanding of dynamics and complexities. This text proposes to problematize the migrations of workers of sport in the scope of the general migrations, revisiting theoretical elaborations that interpreted this mobility of athletes.
\end{abstract}

Keywords: Migration. Workers of Sport Migration. Sport. Globalization. World-System.

\section{RESUMEN}

En el deporte contemporáneo es común encontrar atletas a representar equipos de nacionalidades que no la suya, siendo que en algunas modalidades los jugadores extranjeros se encuentran en su mayoría en relación a los nacionales. Por otro lado es también común constatar la presencia de atletas que, en virtud de cambio de nacionalidad, representan otros países que no el suyo. Estas situaciones resultan de migraciones de trabajo deportivo, en que los atletas a semejanza de otros trabajadores atravesan fronteras de países, impulsados por fuerzas sociales, políticas y económicas que los trascienden. Los enfoques teóricos hechos a este fenómeno, a pesar de los recientes, permiten una comprensión amplia de las dinámicas y complejidades. Este texto se propone problematizar las migraciones de trabajo deportivo en el marco de las migraciones generales, revisitando las elaboraciones teóricas que interpretaron esta movilidad de atletas.

Palabras clave: Migraciones. Migraciones de Trabajo Deportivo. Deportes. Globalización. Sistema-Mundo.

\footnotetext{
${ }^{1}$ Investigador do Centro de Estudos Sociais da UC. E-mail: cmsnolasco@gmail.com
} 


\section{INTRODUÇÃO: ATLETAS EM MOVIMENTO}

Em 2017 o Tour de France foi ganho pela equipa britânica Sky, constituída por três ciclistas britânicos, dois espanhóis, um colombiano, um bielorusso, um alemão e um polaco. ${ }^{2}$ A Euroliga feminina de basquetebol 2016/17, a mais importante competição basquetebolista de mulheres na Europa, foi ganha pela equipa russa Dynamo Kursk, com um plantel constituído por dez jogadoras russas, duas estadounidenses, uma francesa e uma espanhola. ${ }^{3}$ O campeão 2016/17 da NHL, a liga profissional conjunta dos Estados Unidos e Canadá de hóquei no gelo, foi a equipa Pittsburgh Penguins dos EUA, a qual era formada por 15 estado-unidenses, 16 canadianos, três suecos, um finlandês, um checo, um suíço, um russo e um alemão. ${ }^{4} \mathrm{Em}$ 2015, no Campeonato do Mundo de Rugby, 36\% dos jogadores presentes na competição jogavam em equipas de outros países que não o seu. ${ }^{5} \mathrm{O}$ mesmo se passava com 64,8\% dos futebolistas presentes no Campeonato do Mundo de Futebol de 2014, realizado no Brasil. ${ }^{6}$ Por outro lado, no Campeonato do Mundo de Futsal de 2016, para além dos 14 jogadores brasileiros presentes em representação do Brasil, havia mais 25 brasileiros naturalizados, sete pela Itália, seis pelo Azerbaijão, quatro pelo Cazaquistão, quatro pela Rússia, um pelas Ilhas Salomão e um outro pela Espanha. ${ }^{7}$ Estes são alguns exemplos de que em todos os desportos, em todas as competições e em todos os espaços, os atletas estão em movimento (BALE; MAGUIRE, 1994, p. 1). Não o movimento convencional inerente à motricidade dos atletas, mas o movimento resultante da mobilidade migratória dos mesmos.

As migrações de trabalho desportivo não são um fenómeno novo, contudo nos últimos anos intensificaram-se à escala global, tornando-se mais complexas com a diversificação de origens e destinos, bem como dos processos e dinâmicas que lhe são implícitos. Assiste-se hoje à formação de equipas heterogéneas, com atletas de distintas proveniências, identidades, oralidades e etnicidades. Em muitas circunstâncias, os atletas nacionais são minoritários, ou quase ausentes, na constituição dos plantéis das equipas. Tendo em consideração os intensos movimentos migratórios do século XX e início do século XXI, uma parte significativa desta mestiçagem desportiva é resultado de fluxos migratórios gerais. ${ }^{8}$ No entanto, o próprio desporto suscita e alimenta fluxos migratórios próprios em resultado da sua atividade. Por isso, estranho é não encontrar

${ }^{2}$ LE TOUR DE FRANCE. Disponível em: < http://www.letour.fr/le-tour/2017/us/teams/sky.html >. Acesso em: 25 jul. 2017.

3 FIBA BASKETBALL. Disponível em: http://www.fiba.com/europe/euroleaguewomen/2017/Dynamo-Kursk\#tab=roster >. Acesso em: 25 jul. 2017.

${ }^{4}$ NHL.COM. Disponível em: < https://www.nhl.com/penguins/roster/2016 >. Acesso em: 14 maio 2017.

${ }^{5}$ WORLD RUGBY. Disponível em: < http://www.worldrugby.org/tournament/1238/teams >. Acesso em: 20 out. 2015 .

6 FIFA.COM. Disponível em: < http://www.fifa.com/worldcup/archive/brazil2014/teams/team=43860/index.html >. Acesso em: 14 jul. 2014.

7 GLOBO.COM. Globo Esporte. Disponível em:

http://globoesporte.globo.com/eventos/futsal/noticia/2016/09/futsal-globalizado-mundial-tera-25-

brasileiros-defendendo-outros-paises.html >. Acesso em: 3 nov. 2016.

${ }^{8} \mathrm{O}$ exemplo que melhor ilustra a mestiçagem desportiva resultante das migrações gerais, é o da seleção francesa, vencedora do Campeonato do Mundo de Futebol de 1998. Esta equipa, que ficou conhecida como Black, Blanc et Buer, símbolo de uma França multicultural, é reflexo da vocação migrante da sociedade francesa, em simultâneo com a relação colonial para com regiões distantes que foram, ou continuam a ser, territórios gauleses (CARRAD, 2002). 
atualmente atletas a representar clubes que não os da sua nacionalidade, ${ }^{9}$ ou a representar equipas nacionais distintas de países de onde são naturais. A migração de talento desportivo constitui pois uma característica evidente e uma realidade importante no mapa global do desporto, sendo resultado de "[...] uma cultura desportiva contemporânea, onde o crescente trabalho atlético atravessa fronteiras políticas, culturais, étnicas e económicas" (ELLIOTT; MAGUIRE, 2008, p. 482).

Enquanto área de investigação no domínio das Ciências Sociais, este fenómeno constitui uma área recente cujo trabalho se desenvolveu, essencialmente, a partir dos anos noventa. A crescente mobilidade de atletas chamou a atenção para uma realidade que, sendo constatada, era praticamente ignorada nas suas motivações e dinâmicas. As investigações relativas às migrações de trabalho desportivo têm decorrido num espaço híbrido, sendo efetuadas desde quadros teóricos das migrações, bem como desde teorias do desporto, sem contudo haver uma conciliação destes dois campos. Um olhar combinado das duas dimensões analíticas demora a acontecer, desde logo pelas questões epistemológicas das Ciências Sociais que em considerar o desporto como fenómeno socialmente relevante, ao mesmo tempo que estes fluxos migratórios são pouco evidentes no âmbito das migrações gerais.

Neste texto pretende-se revistar as abordagens teóricas desenvolvidas sobre as migrações de trabalho desportivo: começa-se por assinalar os trabalhos percursores que identificaram as mobilidades de atletas como processos migratórios; avança-se para a conceptualização dessas mobilidades como migrações de trabalho desportivo inseridas no amplo processo de globalização; assinalam-se as diversas abordagens que procuram inserir estas migrações desportivas no âmbito de teorias migratórias; conclui-se com a apresentação de trabalhos que sugerem outras abordagens teóricas sobre o tema em causa. Este texto não tem a pretensão de ser exaustivo na revisitação que faz à investigação sobre migrações de trabalho desportivo, mas apenas constituir-se como uma síntese das principais abordagens teóricas que contribuíram para a problematização da complexidade inerente a estas migrações.

\section{PRIMEIRAS ABORDAGENS: IDENTIFICAÇÃO DE UM NOVO FLUXO MIGRATÓRIO}

As primeiras referências não acidentais à mobilidade de atletas e à sua interpretação como movimentos migratórios foram realizadas no âmbito da geografia, inicialmente pelo americano John Rooney (ROONEY, 1969) e depois pelo britânico John Bale (BALE, 1991).

John Rooney, num texto de 1969, Up from the mines and out from the prairies: Some geographical implications of football in the United States, foi o primeiro autor a debruçar-se sobre a migração de atletas. O autor analisou o modo como o futebol americano se implantou nos Estados Unidos, e como as universidades criaram equipas de futebol em representação de interesses locais. Ao estabelecer uma relação entre as universidades e o volume populacional das cidades e Estados em que se localizavam, Rooney constatou que muitas equipas universitárias eram constituídas por jogadores provenientes de outros locais. $\mathrm{O}$ facto de esses jogadores serem predominantemente oriundos de grandes centros urbanos e industriais do país e se deslocarem-se para pequenas cidades, levou o autor a concluir sobre a existência de processos migratórios.

\footnotetext{
${ }^{9}$ No futebol contemporâneo é estranha a condição do clube Athlétic de Bilbao, cujas equipas são constituídas exclusivamente por atletas com naturalidade basca ou descendentes de bascos (ATHLETIC CLUB BILBAO. Disponível em: < http://www.athletic-club.eus/cas/datos-del-club.html >. Acesso em: 16 jun. 2017).
} 
Posteriormente, Ronney $(1974 ; 1980)$ voltou a referir-se à mobilidade dos jogadores de futebol americano, analisando os processos de recrutamento das universidades.

John Bale, com trabalhos efetuados no campo da geografia do desporto, publicou em 1991 um trabalho em que caracteriza o processo de recrutamento internacional de atletas pelas universidades norte-americanas. Apesar de abordar a mesma temática que Rooney, Bale desenvolveu uma análise teórica mais consistente, contextualizando estas migrações no âmbito das dinâmicas de globalização e das estratégias capitalistas internacionais. $\mathrm{O}$ autor assinala, em três escalas distintas, as condições reunidas pelos Estados Unidos para a mobilidade dos atletas universitários: a nível global, a existência de um contexto concorrencial que incentiva à competição; a nível nacional, a manutenção de uma ideologia política e social de individualismo que incentiva ao triunfo; a nível local, a vitória como um imperativo face à necessidade das universidades publicitarem e justificarem os patrocínios que auferem. Transversal a estas três escalas encontra-se a ideologia competitiva, incentivadora da livre iniciativa e valorativa do triunfo, promovendo um ethos desportivo que legitima e torna viável o recrutamento de atletas estrangeiros com perfil vencedor. Segundo Bale, o poder sedutor dos Estados Unidos, juntamente com a sua capacidade remuneratória, as condições para a prática desportiva e o contexto de intensa competição, tornaram o país num destino inevitável dos fluxos migratórios de atletas, frustrando as tentativas, por parte dos países de origem, de manter os seus melhores atletas.

Bale não se limita a uma observação tipicamente geográfica, centrada na descrição espacial das relações sociais. Problematiza as relações a nível social, cultural e político, sendo isso evidente quando o autor aborda a controvérsia relativa ao recrutamento de atletas estrangeiros desde a dupla perspetiva dos locais de origem e destinos. $\mathrm{O}$ autor refere-se à forma como os atletas estrangeiros ocupam vagas e posições que seriam naturalmente ocupadas pelos atletas americanos, bem como ao impacto negativo que o recrutamento de atletas estrangeiros, efetuado pelas universidades norte-americanas, tem nos países de onde esses atletas são originários. Bale assume também um olhar prospetivo, afirmando que os movimentos migratórios de atletas talentosos serão um tema de estudo premente, nomeadamente porque esses movimentos tendem a intensificar-se, bem como a suscitar questões relativas ao impacto que terão no movimento olímpico e nas competições internacionais.

Os trabalhos de Rooney e Bale são relevantes pelas abordagens pioneiras que fazem às migrações desportivas, permitindo identificar este novo fluxo migratório. John Rooney vai mais além das análises de distribuição geográfica do fenómeno desportivo, procurando padrões que determinem a relação entre o espaço e os fluxos que nele decorrem. John Bale contribui com novas abordagens teóricas do desporto, em concreto uma leitura informada pela história, cultura e economia e em que as dinâmicas espaciais de globalização suscitam processos de mobilidade espacial de atletas.

\section{A MigraÇão de ATLETAS NA ARENA DESPORTIVA GLOBAL}

Em 1994 foi publicado The Global Sports Arena: athletic talent migration in an interdependent world, obra organizada por John Bale e Joseph Maguire (BALE; MAGUIRE, 1994), que veio a constituir a referência primordial dos estudos das migrações de trabalho desportivo. Em primeira instância, a sua importância reside no facto de reunir o contributo de autores que abordam o fenómeno desportivo desde distintas perspetivas disciplinares, observando as migrações em diversas modalidades, em diferentes espaços e escalas geográficas. Num segundo momento, a obra é relevante pela afirmação das migrações desportivas como um segmento das migrações 
contemporâneas, determinado pelas tendências de globalização desportiva (BALE; MAGUIRE, 1994).

Para Bale e Maguire (1994) as migrações de atletas inserem-se na ampla dinâmica de mobilidade social e geográfica característica das modernas sociedades industriais. É importante esta afirmação, pois assume o desporto como fenómeno social, condicionado e condicionante da realidade em que se encontra inserido, e não como fenómeno autónomo e independente do contexto que o produz. O progressivo aumento de agências internacionais, o desenvolvimento de formas de comunicação global, o exacerbar da concorrência económica à escala planetária, e o desenvolvimento de formas de direito e cidadania que se normalizam a nível internacional têm consequências no desporto, nomeadamente: na criação de organizações desportivas internacionais; estandardização e universalização das regras das várias modalidades; incremento da competição individual, nacional e internacional; na criação de mega eventos desportivos globais. Todos estes fatores promovem a mobilidade e circulação migratória de atletas. Nesta perspetiva, as migrações de trabalho desportivo ocorrem na sequência da industrialização e mercadorização do desporto, bem como da constituição de um sistema desportivo global, o qual, por sua vez se encontra inserido no mais abrangente processo de globalização. Assim, as migrações de trabalho desportivo, ocorrendo em paralelo com outros fluxos, nomeadamente de tecnologia, economia, imagens e ideias, estão intimamente associadas às paisagens globais propostas por Appadurai (1990).

$\mathrm{O}$ argumento da existência de uma "arena desportiva global" seguiu a tendência linear e homogénea do conceito hegemónico de globalização. Os vários estudos de caso apresentados na obra, tendem a variar apenas na especificidade de cada desporto, seguindo uma linha argumentativa que remete para uma estandardização de processos. Apesar de serem sugeridas diferentes abordagens teóricas sobre as migrações de atletas, que vão desde a modernização ao imperialismo, passando pela teoria da dependência e pelo sistema-mundo de Wallerstein, a ampla sugestão teórica é a de que os processos de globalização determinam estes fluxos migratórios.

Nesta linha argumentativa, em obra posterior, Joseph Maguire et al. (2002, p. 4) reforçam a ideia de arena desportiva global, afirmando que o mundo do desporto é um campo competitivo, marcado por relações de poder, no qual ocorrem lutas dentro e fora do terreno de jogo. Essa competição global manifesta-se em cinco dimensões: migratórias; económicas; tecnológicas; comunicacionais e ideológicas. A migração de pessoas surge, mais uma vez, como uma característica do cenário desportivo global. Sejam atletas, treinadores, managers, agentes, preparadores físicos, entre outros, todos circulam nas paisagens globais a par de mercadorias ou merchandising desportivo, de aparatos tecnológicos que potenciam desempenhos, de formas de comunicação que difundem as competições, e de conceções ideológicas liberais que promovem a mobilidade de circulação de pessoas e bens.

Raffaele Poli (2010), desde uma perspetiva crítica, afirma que as abordagens efetuadas no campo conceptual da globalização reproduzem, ainda que com algumas especificidades, a ideia de interconexão política e económica, do desaparecimento de fronteiras, da existência de um espaço partilhado e de novas relações sociais. São de três tipos as interpretações das migrações desportivas no âmbito da globalização. Em primeiro lugar, os céticos afirmam que a globalização não é algo de novo, mas sim uma fase que corresponde à intensificação de processos que se originaram com a difusão do capitalismo. Por isso o intenso processo migratório de desportistas que ocorre desde os anos 80/90 do século XX teve origem ainda no século XIX, não se podendo criar uma rutura nessa continuidade histórica como se anteriormente não houvesse migrações de atletas (LANFRANCHI; TAYLOR, 2001). Em segundo lugar, os hiperglobalistas 
apresentam a globalização como o quadro conceptual primordial de entendimento do mundo contemporâneo, em que as relações são integradas à escala global, transcendendo os Estados. Este olhar, aplicado à interpretação das migrações de trabalho desportivo remete para a novidade implícita no volume inusitado de atletas que nas últimas décadas compuseram os fluxos, na forma como esta novidade aconteceu em distintas modalidades, afetou diferentes espaços e determinou o perfil das competições, como se de uma inevitabilidade se tratasse. Finalmente, em terceiro lugar, os transformacionistas que consideram a globalização como consequência e não como causa de transformações ocorridas a nível tecnológico, económico, político e cultural, sendo que essas mudanças não convergem para uma integração homogeneizadora das sociedades, mas para novas formas de estratificação das sociedades e para uma nova sociedade mundial. Esta perspetiva transformacionista, aplicada às migrações de atletas, remete para um entendimento de que os espaços desportivos nacionais estão integrados num todo subordinado a uma lógica mundial de competitividade predominantemente económica e financeira, sendo a mobilidade migratória percebida como funcional para um sistema que se metamorfoseou de desportivo em economicista.

\section{MigRAÇõES DE ATLETAS NO SISTEMA-MUNDO DESPORTIVO}

Mais de 20 anos passados desde a publicação do The Global Sports Arena (BALE; MAGUIRE, 1994), constata-se que a produção académica sobre a migração de atletas diversificou as abordagens conceptuais. Reconhece-se que o aumento dos fluxos internacionais de atletas migrantes não ocorre espontaneamente como consequência natural da globalização. Essas migrações, longe de serem absorvidas por uma globalização sem fronteiras, são fortemente tributárias de relações instauradas entre Estados, relações culturais, históricas e jurídicas que obrigam a uma interpretação relacional entre espaços de origem e de destino (POLI, 2010).

À semelhança dos estudos das migrações gerais, a investigação sobre migrações de desportistas passou, nos últimos anos, a assumir como dimensão analítica as desigualdades entre países, realçando mecanismos políticos e económicos de dominação. O facto de muitos trabalhos dedicarem particular atenção aos fluxos migratórios Sul/Norte, com origem em África ou na América Latina e destino na Europa ou América do Norte (DARBY, 2000; DARBY; AKINDES; KIRWIN, 2007; POLI; BESSON, 2011), motivou interpretações de pendor crítico/marxista, em que esses fluxos são vistos como formas de exploração do Sul pelo Norte global.

Neste âmbito, emergiram interpretações a partir da teoria do sistema-mundo e do desenho conceptual de Immanuel Wallerstein. Na teoria do sistema-mundo, as clivagens entre espaços são estruturantes e os países são distribuídos numa escala que vai do centro à periferia, em função dos poderes, capacidade e recursos que detêm. É importante assinalar que o centro e a periferia no desporto não são exatamente coincidentes com o centro e periferia convencionais (TAYLOR, 2006). O sistemamundo desportivo não é uniforme e coerente, havendo variações nos espaços estruturais de poder em conformidade com as modalidades desportivas em apreço. A este propósito Lee e Lin (2007) identificam os Estados Unidos como espaço central no basebol, sendo a Europa uma área externa, enquanto Magee e Sugden (2002) apontam a Europa como centro do futebol mundial e os Estados Unidos surgem como periféricos. ${ }^{10}$ No

10 Apesar dos EUA serem uma potência do futebol feminino, com três títulos mundiais ganhos (FIFA.COM. Disponível em:

http://www.fifa.com/womensworldcup/index.html?intcmp=fifacom hp_module tournaments >. Acesso em: 14 ago. 2017), e se encontrarem em primeiro lugar do ranking de futebol feminino (FIFA.COM. 
basquetebol os Estados Unidos são o centro, mas no andebol o centro já corresponde aos países europeus. Por isso, consoante o desenvolvimento dos desportos é possível falar em americanização, europeização, japoneização, asianeização e até hispanização e africanização (MAGUIRE, 2011a). A este propósito, Magee e Sugden (2002) analisam a migração de futebolistas para Inglaterra, recorrendo ao modelo do sistemamundo - o futebol entendido como veículo de valores, ideologias e modos de vida ocidentais, característicos dos países dominantes do centro que, ao dispersar-se pelo mundo, contribuiu para o desenvolvimento do capitalismo moderno. Os movimentos migratórios de atletas decorrem em sentido inverso, ou seja, devido à industrialização do desporto e das exigências competitivas nos países do centro, os atletas originários dos países periféricos que revelem talento e competências desportivas migram para os países centrais. Também Matthew Taylor (2006) considera que a forma adequada de conceptualizar todos os processos migratórios de atletas é considerá-los como movimentos de trabalho desportivo da periferia para o centro.

Em muitos desportos, a observação das migrações de atletas tem o sentido periferia/centro, ou seja, das zonas mais carenciadas para as mais desenvolvidas. No futebol esses movimentos têm ocorrido da periferia europeia para os países europeus do centro e da América Latina e África para a Europa (LANFRANCHI; TAYLOR, 2001; TAYLOR, 2006). Carmen Rial (2008) a propósito das migrações de futebolistas brasileiros, diz que mesmo quando o movimento os leva para uma cidade vizinha maior, ou para outro Estado, seguem uma orientação no sentido da periferia para o centro. Eduardo Galeano, de forma simples, desenha esse itinerário:

\begin{abstract}
Ao sul do mundo, este é o itinerário do jogador de futebol com boas pernas: da sua aldeia passa para uma cidade do interior; da cidade do interior passa para um pequeno clube da capital do país; na capital, o clube pequeno não tem outro remédio que não seja vendê-lo a um clube grande; o clube grande, asfixiado em dívidas, vende-o a outro clube mais grande de um país maior; e finalmente o jogador coroa a sua carreira na Europa (GALEANO, 2006, p. 19).
\end{abstract}

As razões para este tipo de ocorrência são relativamente fáceis de identificar, tendo já sido assinaladas pela teoria neoclássica das migrações, especificamente pelo modelo push-pull quando se confrontam dois lugares com indicadores de desenvolvimento distintos: do lado dos fatores repulsivos está a fraqueza das economias nacionais de pertença, as crises financeiras, a debilidade das estruturas que organizam o desporto, a precariedade das instalações desportivas; do lado da atração estão os fatores inversos, ou seja, a pujança económica, a estabilidade financeira, a fortaleza das organizações, a qualidade das infraestruturas desportivas, a existência de torneios e campeonatos mais competitivos e mediáticos.

A sistemática orientação migratória de atletas do Sul para o Norte, e ainda o facto de a muitos desses atletas ser atribuída a nacionalidade do país de destino, tem sido interpretada como uma fuga de recursos humanos por parte dos países de origem. À semelhança do que se passou com o conceito de brain drain, utilizado nos anos 1960 para expressar a "fuga de cérebros" dos países da Europa, inicialmente para os Estados Unidos, também se recorreu a conceitos como brawn drain (BALE, 1991), muscle drain (ANDREFF, 2009), fuga de pés (RIAL, 2006) ou muscle exodus (HOBERMAN, 2007), para caracterizar o processo imigratório de atletas como uma perda. Os conceitos têm

Disponível em: 
sido utilizados consoante a modalidade desportiva, sendo que no futebol se recorre mais ao conceito de feet drain ou fuga de pés.

Esta "fuga" migratória de atletas da periferia para o centro também pode ser interpretada a partir da teoria da dependência (DARBY, 2000; 2006). Este quadro conceptual foi trabalhado por Andre Gunder Frank, com a argumentação de que o sistema capitalista, dominado pelos países industrializados do centro, é o principal motor de subdesenvolvimento dos países periféricos e enquanto este sistema se mantiver é irrealista ponderar o desenvolvimento do "terceiro mundo". Para a superação do subdesenvolvimento das periferias será necessária uma rutura com as condições de manutenção da dependência, subvertendo a lógica capitalista. Uma das vantagens em utilizar a teoria da dependência no âmbito dos estudos sobre desporto, é que esta permite perceber a natureza das relações entre o primeiro e o terceiro mundo desportivo a partir de uma perspetiva histórica (DARBY, 2000). Olhando em particular para o futebol africano, assinala-se que a posição dominante do futebol dos países europeus criou condições para manter o futebol em África numa situação de dependência. O principal beneficiário da condição dependente do futebol africano é o futebol europeu, que assim consolidou a condição de futebol central no sistema-mundo futebolístico. Essa posição dominante é possível de ser constatada na forma desproporcionada como a Europa é representada nas competições mundiais, bem como na forma quase monopolista como gere a dimensão económica e política do futebol mundial. Assim, a sistemática desqualificação do futebol africano através da emigração de futebolistas para os clubes europeus exemplifica a forma como funciona o desenvolvimento dependente.

A apropriação dos jogadores africanos por parte dos clubes europeus, para utilização nas competições internas e internacionais, é um exemplo claro de como, de forma imperialista e colonial, os países centrais mantêm um sistema de subdesenvolvimento e exploração noutras partes do mundo. Até ao fim dos impérios coloniais, os melhores jogadores africanos das colónias francesas, portuguesas e belgas migravam para as respetivas metrópoles para integrarem os clubes nacionais ou jogarem pela equipa nacional, num claro aproveitamento colonial das potencialidades desses jogadores (LANFRANCHI; TAYLOR, 2001). Num contexto pós-colonial esta situação intensificou-se com as exigências competitivas do futebol europeu, reforçando-se com a proliferação de agentes desportivos, com o scout de busca de novos talentos e a criação de escolas de formação futebolística patrocinadas por clubes europeus.

Trabalhando também sobre as migrações de atletas das periferias para o centro, em particular os fluxos de futebolistas sul-americanos e africanos para a Europa, Raffaele Poli (2006) analisa esses movimentos à luz da teoria das vantagens comparativas. Esta teoria foi desenvolvida essencialmente para explicar as relações comerciais internacionais, afirmando que apesar de os países poderem produzir distintos bens, devem especializar-se naquele que lhe traz mais vantagens, combinando $o$ benefício de produzir ao menor custo e de forma mais eficiente um produto de melhor qualidade, daí retirando benefícios quando esse produto é transacionado nos mercados internacionais. Ou seja, os países exportam o que produzem internamente de forma eficiente, importando o que o trabalho interno é ineficiente a produzir. A teoria das vantagens comparativas é aplicada às migrações de trabalho desportivo por Poli (2006), quando o autor refere que determinados países são detentores de um conjunto de recursos humanos que lhes permite estabelecer um rácio qualidade/custo que lhes é favorável. Esses recursos são essencialmente a mão-de-obra barata e um elevado contingente de jovens atletas desejosos de jogarem na Europa. 
As estratégias de potenciar as vantagens comparativas contribuem para que, por exemplo, muitos países na América do Sul e África se tenham especializado na produção de futebolistas, que posteriormente exportam para a Europa ou a Ásia, gerando elevados rendimentos (POLI; BESSON, 2011). Para os clubes europeus é vantajoso contratar jogadores que, apesar de jovens, já apresentam indicadores de bom desempenho desportivo e com os quais é possível especular no mercado internacional de transferências. Esta estratégia de recrutamento por parte dos clubes europeus é mantida por uma densa rede de agentes de jogadores, investidores, clubes e treinadores que laboram numa vasta escala geográfica.

Apesar das abordagens efetuadas no âmbito da teoria do sistema-mundo e das aproximações neoclássicas às escolhas dos atletas enquanto migrantes, é preciso ter em consideração que cada fluxo migratório tem especificidades que estão para além de determinações macroeconómicas e das leis de procura e oferta do mercado (MEYER, 2001). A ênfase colocada na questão económica pode encobrir outras dimensões e expressões do processo global de circulação de atletas (MAGUIRE, 2004).

As relações que decorrem entre centro e periferia não podem ser interpretadas de forma estática, subordinadas exclusivamente à existência diferenciada de recursos, devendo-se privilegiar uma abordagem relacional entre protagonistas que atuam em função de variáveis históricas, políticas e culturais (POLI, 2010). Assim, de forma geral, os jogadores naturais de países onde os clubes não são financeiramente bem dotados, emigram para clubes europeus mais ricos, sendo esse processo migratório seletivo em função de aspetos relacionais. Quando se observam os contingentes migratórios de futebolistas na Europa, é possível perceber, através da sobrerepresentação de jogadores de determinadas proveniências, o caráter relacional e seletivo do processo migratório de atletas. Assim, os clubes ingleses, quando recrutam jogadores estrangeiros, fazem-no predominantemente nos outros espaços nacionais do Reino Unido, nomeadamente na Irlanda do Norte, Escócia e Gales, privilegiando também os países vizinhos do norte da Europa e ainda países com os quais têm particular afinidade, como os Estados Unidos ou a Austrália. Os clubes alemães quando contratam jogadores estrangeiros fazem-no predominantemente junto dos seus vizinhos da Europa de Leste. A França privilegia fundamentalmente jogadores de origem africana, em particular das suas ex-colónias. Os clubes espanhóis e italianos têm como jogadores estrangeiros futebolistas provenientes predominantemente da América Latina, em particular argentinos e uruguaios (POLI, 2010; POLI; BESSON, 2011). Por sua vez, os clubes portugueses privilegiam a contratação de jogadores brasileiros (NOLASCO, 2013). Estas preferências não anulam a tendência cosmopolita da constituição dos plantéis, contudo, revelam a existência e manutenção de vínculos históricos e culturais que determinam os fluxos migratórios de trabalho desportivo (MAGUIRE; STEAD, 1998).

Esta preferência ou seletividade migratória pode ser interpretada como uma das características da colonialidade global. Segundo Ramón Grosfoguel (2008), a colonialidade é uma forma colonial contemporânea em que, apesar da ausência de administração colonial, há uma continuidade nas práticas coloniais de relacionamento. As análises aos processos migratórios de atletas que estabeleçam uma relação de força entre o centro e a periferia, em que os países centrais dominam e controlam os fluxos através de múltiplos agentes e processos, remete para esta relação colonial sofisticada. Apesar da ausência de uma administração colonial, verifica-se o exercício de poder por parte das instituições que administram globalmente o desporto, que tolera ou promove o deskilling das semiperiferias e periferias nos termos e condições determinadas pelos países centrais. Os mais talentosos, qualificados e competentes trabalhadores, nos quais as periferias e semiperiferias investiram tempo e recursos na sua formação, são atraídos 
para o centro, cuja riqueza deriva precisamente do controlo sobre o trabalho atlético no sistema de produção de desporto e lazer (MAGEE; SUGDEN, 2002; CONNOR; GRIFFIN, 2009).

As abordagens teóricas desenvolvidas sobre as mobilidades de atletas incidiram essencialmente no desporto hegemónico, profissionalizado e mediatizado, dedicando particular atenção à forma como as dinâmicas capitalistas determinam as mobilidades de atletas. No entanto outras abordagens foram desenvolvidas, privilegiando outros espaços e outras dimensões das migrações de trabalho desportivo. A este propósito importa referir os trabalhos de Sine Agergaard, que em coautoria (AGERGAARD; BOTELHO, 2013; AGERGAARD; ENGH, 2017), incidem sobre as migrações de mulheres atletas, tendo em consideração essencialmente os países escandinavos como destino, bem como as dimensões sociais, culturais, religiosas e étnicas relativamente à integração das mulheres protagonistas dessas migrações. Também o trabalho de Lenita Ruggi (2009), sobre as representações com que os jogadores de futebol brasileiros concebem destinos e percursos migratórios, constitui como um campo temático importante, pois assume uma dimensão subjetiva dos sujeitos migrantes enquanto determinante do processo migratório. Por sua vez, a investigação de Nolasco (2013) sobre as migrações no futebol português, desenvolve uma síntese entre diversas dimensões teóricas, nomeadamente entre as teorias gerais das migrações com o conceito de semiperiferia aplicado à sociedade portuguesa. Constatando a simultaneidade entre o enorme número de jogadores estrangeiros a representar clubes portugueses, bem como elevado número de jogadores portugueses contratados por clubes estrangeiros, explora esse paradoxo a partir da condição semiperiférica da sociedade portuguesa e da forma como o futebol nacional desenvolve estratégias de rentabilização das migrações de jogadores. Funcionando como uma "placa giratória" que recebe e distribui recursos humanos, o futebol português desenvolve uma estratégia de imigração de jogadores "baratos", para os rentabilizar desportiva e financeiramente, transferindo-os posteriormente por valores mais elevados, sendo que neste processo de saída se encontram também os jogadores portugueses. Esta estratégia revela que as migrações de trabalho desportivo não são um fenómeno simples e uniforme, mas que têm as especificidades dos espaços que estão nas origens, destinos e intermediação dos fluxos.

\section{CONSIDERAÇÕES FINAIS}

Encontrando-se as sociedades contemporâneas na era das migrações (CASTLES; MILLER, 2003), nas quais as mobilidades espaciais dos indivíduos são uma inevitabilidade, a migração de atletas constitui-se como uma consequência do competitivo universo do trabalho desportivo.

As condições em que decorrem as migrações internacionais de atletas suscitam um complexo de interdependências e relacionamentos que não são apenas produto do desporto. Para além da omnipresença das variáveis económicas, outras dimensões devem ser levadas em consideração no mapeamento destes fluxos migratórios, até porque as migrações desportivas, sendo afetadas pelo "complexo industrial desportivo" (MAGUIRE; FALCOUS, 2011), são-no também por variáveis históricas, políticas, culturais, geográficas ou étnicas, entre outras (LANFRANCHI; TAYLOR, 2001; MCGOVERN, 2002; TAYLOR, 2006; POLI; BESSON, 2011).

No âmbito desportivo, as questões suscitadas pelas migrações internacionais de trabalho não são novidade. Já no início do século XX, em determinadas modalidades, a migração de atletas suscitou problemas relacionados com estatutos profissionais, duplicidade na representação de clubes e países, e até questões jurídicas relativas à 
legítima migração desses atletas em função da sua nacionalidade (DIETSCHY, 2006). Com a intensificação destas migrações, o mundo do desporto foi progressivamente confrontado com questões que já anteriormente haviam sido suscitadas pelas migrações gerais, nomeadamente: as consequências para os países de origem da saída destes trabalhadores e o seu impacto nos sistemas desportivos dos países de destino; a regulação destes fluxos migratórios por parte das organizações desportivas nacionais e internacionais; os critérios de permanência e exercício laboral nos países de destino; os direitos de cidadania dos atletas nos espaços geopolíticos para onde migram e no âmbito das modalidades desportivas que praticam.

Emergindo de um processo global de celebração do fenómeno desportivo, a migração de atletas considerada como algo não problemático. Contudo, os fluxos migratórios resultam de um conjunto de verdades inconvenientes, como o complexo processo de industrialização do trabalho desportivo, da comercialização da força laboral desportiva, e da luta pelo poder que caracteriza o desporto global (MAGUIRE, 2011b). Por consequência, nesta "idade das migrações" importa que as investigações sobre as migrações de atletas incidam sobre temas que até ao momento foram pouco ou nada explorados, como por exemplo: as migrações de jovens atletas, que contrariando a regulamentação imposta por instâncias internacionais relativamente às transferências de jovens, são intensamente procurados para rentabilização desportiva e financeira dos clubes; as transferências internacionais de atletas efetuadas para clubes de escalões secundários e para o desporto amador, onde não há o mediatismo nem a visibilidade proporcionada pela comunicação social, e nas quais os processos migratórios terão formas específicas de acontecer; as migrações de atletas mulheres, que face à crescente importância do desporto por elas praticado também são procuradas internacionalmente, sendo importante verificar se têm formas específicas de acontecer, se seguem os mesmos itinerários e orientação, ou se reproduzem processos diferentes do desporto praticado por homens; a comparação entre processos migratórios em distintas modalidades desportivas, procurando conhecer se em função dos desportos se alteram origens e destinos dos migrantes, a sua expressão e volume; os processos de naturalização de atletas estrangeiros com vista à utilização nas seleções nacionais; a posição das entidades públicas e privadas que regulam o desporto, a nível nacional e internacional, relativamente a um mercado liberalizado de migrações. Todos estes domínios temáticos abrem novas possibilidades ainda por explorar, nomeadamente trabalhos de síntese entre teorias sociais do desporto e teorias gerais das migrações.

\section{REFERÊNCIAS}

AGERGAARD, S.; BOTELHO, V. The way out? African players' migration to Scadinavian women's football. Sport in Society, v. 17, n. 4, p. 523-53, 2013.

AGERGAARD, S.; ENGH, M. H. Globalization, migration and race in sport. In: NAURIGHT, J.; WIGGINS, D. K. (Orgs.). Routledge Handbook of Sport, Race and Ethnicity. Londres: Routledge, 2017. p. $107-120$.

ANDREFF, W. The economic effects of 'muscledrain' in sport. Birkbeck Sport Business Centre Research Paper Series, v. 2, n. 2, p. 9-31, 2009.

APPADURAI, A. Disjuncture and difference in the global cultural economy. In: FEATHERSTONE, M. (Org.). Global culture. Londres: Sage, 1990. p. 295-310.

BALE, J. The brawn drain: foreign student-athletes in American Universities. Chicago: University of Illinois Press, 1991. 
BALE, J.; MAGUIRE, J. (Orgs.). The global sports arena: athletic talent migration in an interdependent world. Londres: Frank Cass, 1994.

CARRAD, P. L'equipe de France du monde: sport and national identity. French Cultural Studies, n. 13, p. 65-82, 2002.

CASTLES, S.; MILLER, M. The age of migration. International population movements in the modern world. New York: Palgrave Macmillan, 2003.

CONNOR, J.; GRIFFIN, A. The muscle trade: international track and field athlete mobility, colonialism and development. In: TASA CONFERENCE, 2009, Canberra, Austalia. Annual... Canberra, 2009. p. 113.

DARBY, P. Migrações para Portugal de jogadores de futebol africanos: recurso colonial e neocolonial. Análise Social, n. 179, p. 417-433, 2006.

DARBY, P. Africa's place in FIFA's global order: a theoretical frame. Soccer \& Society, v. 1, n. 2, p. 36-61, 2000.

DARBY, P.; AKINDES, G.; KIRWIN, M. Football academies and the migration of african football labor to Europe. Journal of Sport and Social Issues, n. 31, p. 143-161, 2007.

DIETSCHY, P. Football players' migrations: a political stake. Historical Social Research, v. 31, n. 1, p. 31-41, 2006.

ELLIOTT, R.; MAGUIRE, J. Thinking outside the box: exploring a conceptual synthesis for research in the area of athletic labor migration. Sociology of Sport Journal, v. 25, n. 4, p. 482-497, 2008.

GALEANO, E. Futbol a sol y sombra. Madrid: Editores Siglo XXI de España, 2006.

GROSFOGUEL, R. Para descolonizar os estudos de economia política e os estudos pós-colonais: transmodernidade, pensamento de fronteira e colonialidade global. Revista Crítica de Ciências Sociais, n. 80 , p. $115-147,2008$.

HOBERMAN, J. Race and athletics in the twenty-first century. In: HARGREAVES, J.; VERTINSKY, P. (Orgs.). Physical culture, power, and the body. Oxon: Routledge, 2007. p. 208-231.

LANFRANCHI, P.; TAYLOR, M. Moving with the ball. The migration of professional footballers. Oxford: Berg, 2001.

LEE, P. C.; LIN, C. Y. The Global Flows of International Professional Baseball System. The Sport Journal, v. 10, n. 4, 2007. Disponível em: < http://www.thesportjournal. org/article/global-flowsinternational-professional-baseball-system >. Acesso em: 15 jul. 2017.

MAGEE, J.; SUGDEN, J. The world at their feet. Professional football and international labor migration. Journal of Sport \& Social Issues, v. 26, n. 4, p. 421-437, 2002.

MAGUIRE, J. Preliminary observations on globalization and the migration of sport labour. In: MAGUIRE, J.; FAlCOUS, M. (Orgs.). Sport and migration. Borders, boundaries and crossings. Londres: Routledge, 2011a. p. 73-87.

MAGUIRE, J. Cruzando fronteras: comprendiendo el sentido de la migración y el deporte. EFDeportes, v. 15, n. 154, 2011b. Disponível em: < http://www.efdeportes.com/efd154/comprendiendo-el-sentido-dela-migracion-y-el-deporte.htm $>$. Acesso em: 18 ago. 2017.

MAGUIRE, J. Sport labor migration research revisited. Journal of Sport \&Social Issues, v. 28, n. 4, p. 477-482, 2004. 
MAGUIRE, J.; FALCOUS, M. Introduction. Borders, boundaries and crossings: sport, migration and identidies. In: MAGUIRE, J.; FALCOUS, M. (Orgs.). Sport and migration. Borders, boundaries and crossings. Londres: Routledge, 2011. p.1-12.

MAGUIRE, J.; JARVIE, G.; MANSFIELD, L.; BRADLEY, J. Sport Worlds. A sociological perspective. Lees: Human Kinetics, 2002.

MAGUIRE, J.; STEAD, D. Border crossings: soccer labour migration and the European Union. International Review for the Sociology of Sports, v. 33, n. 1, p. 59-73, 1998.

MCGOVERN, P. Globalization or internationalization? Foreign footballers in the English League, 194695. Sociology, v. 36, n. 23, p. 23-42, 2002.

MEYER, J. B. Network approach versus brain drain: lessons from the diaspora. International Migration, v. 5, n. 39, p. 91-10, 2001.

NOLASCO, C. Tchau Brasil, alô Portugal! A migração de futebolistas brasileiros para Portugal. In: PINHEIRO, F.; MELO, V. A. (Orgs.). A Bola ao ritmo do fado e samba. 100 anos de relações lusobrasileiras no futebol. Porto: Afrontamento, 2013. p. 323-342.

POLI, R. Understanding globalization through football. The new international division of labour, migratory channels and transnational trade circuits. International Review for the Sociology of Sport, v. 45, n. 4, p. 491-506, 2010.

POLI, R. Africans' status in the European football players' labour market. Soccer \& Society, v. 2, n. 2, p. 278-291, 2006.

POLI, R.; BESSON, R. From the south to Europe: a comparative analysis of African and Latin American football migration. In: MAGUIRE, J.; FALCOUS, M. (Orgs.). Sport and migration. Borders, boundaries and crossings. Londres: Routledge, 2011. p. 15-30.

RIAL, C. Rodar - a circulação dos jogadores de futebol brasileiros no exterior. Horizontes Antropológicos, n. 30, p. 21-65, 2008.

RIAL, C. Jogadores brasileiros na Espanha: emigrantes, porém... Revista de Dialectología y Tradiciones Populares, v.61, n. 2, 163-190, 2006.

ROONEY, J. The Recruting Game. Lincoln: University of Nebraska Press, 1980.

ROONEY, J. A Geography of American Sport. Reading: Addison Wesley, 1974.

ROONEY, J. Up from the mines and out from the prairies: Some geographical implications of football in the United States. Geographical Review, v. 59, n. 3. p. 471-492, 1969.

RUGGI, L. Sonhos em campo: transferências internacionais de futebolistas brasileiros. São Paulo: Blucher Acadêmico, 2009.

TAYLOR, M. Global players? Football, migration and globalization, c. 1930-2000. Historical Social Research, v. 31, n. 1, p. 7-30, 2006.

Recebido em: 26 ago. 2017.

Aprovado em: 27 out. 2017. 